Discussion Paper No. $\quad 530$

\title{
HUMAN CAPITAL ACCUMULATION OF SALARIED AND SELF-EMPLOYED WORKERS
}

\author{
Daiji Kawaguchi
}

The Third ISER-Moriguchi Prize (2001) Awarded Paper

March 2001

The Institute of Social and Economic Research Osaka University

6-1 Mihogaoka, Ibaraki, Osaka 567-0047, Japan 


\title{
Human capital accumulation of salaried and self-employed workers
}

\author{
Daiji Kawaguchi ${ }^{1} 2$
}

October 6, 2000

\footnotetext{
${ }^{1}$ Daiji Kawaguchi: Economics Department, 101 Marshall Hall, Michigan State University, East Lansing, MI 48823 USA. Tel: 517-353-9935 Fax: 517-432-1068 E-Mail:kawaguc2@msu.edu

${ }^{2}$ I would like to thank David Neumark, Gerhard Glomm, Jeff Biddle, Linda Bailey, Facundo Sepulveda for helpful comments. I also would like to thank Catherine Fleck for advice on English. All remaining errors are of course mine.
} 


\begin{abstract}
Both human capital accumulation and Lazear contracts can explain the raising wage of salary/wage worker through job experience or tenure. To distinguish between these two effects, Lazear and Moore (1984) used self-employed workers' wage growth to partial out the effect of human capital accumulation from salary/wage workers' wage growth. When the human capital accumulation behavior is identical across two kinds of jobs, the difference in wage growth between salary/wage workers and self-employed workers are due to Lazear contract since self-employed workers' wage are determined by their productivity. However, in the model developed in this paper, when selfemployed workers face more wage variation but enjoy a higher return for human capital, human capital accumulation for those two kinds of jobs are shown to be different. The model predicts that workers with higher human capital select to be self-employed. Under general assumptions on human capital production technology, workers with high human capital have flatter wage-experience profile as a result of optimal human capital accumulation. Thus the heterogeneity of salary/wage and self-employed workers that induces a different pattern of human capital accumulation can explain the observed lower wage growth of self-employed workers inLazear and Moore (1984).
\end{abstract}




\section{Introduction}

Worker's wage growth with work experience is one of the most robust empirical findings in economics. Lazear (1979) and Lazear (1981) explained wage growth among salary/wage workers based on principal-agent theory. In his model, worker's behavior is not perfectly observed and worker's shirking is detected only by chance. In Lazear model, it is optimal for an employer to pay his employee less than the worker's marginal product when the worker is young and more than the worker's marginal product when the worker is old. The employer takes the difference between marginal product and wage when worker is young and returns it to the worker when the worker is old. This payment system discourages workers from shirking since the worker is fired when the shirking is detected and thus cannot take his money back.

A difficulty of testing this theory is that the human capital theory also predicts wage growth with work experience because of worker's skill formation. Since Lazear theory and human capital theory are not mutually exclusive, it is very difficult to attribute the observed wage growth to the specific theory.

As an indirect test of Lazear theory, Lazear and Moore (1984) compared wage growth of salary/wage workers and self-employed workers. Since selfemployed workers do not have an incentive to shirk, the wage growth of self-employed workers can be attributed to the human capital accumulation. Assuming identical human capital accumulation between salary/wage (SW) workers and self-employed (SE) workers, the difference of wage growth be- 
tween SW workers and SE workers can be attributed to Lazear theory. In fact Lazear and Moore (1984) found the steeper wage-experience profile among SW workers than SE workers and used the finding as a supporting evidence of Lazear theory.

The purpose of this paper is to propose the model that predicts the flatter wage-experience profile among SE workers only based on the human capital theory. To develop the model, two crucial aspects of self-employment that differentiate self-employment from salary/wage job are considered. As mentioned in many studies (Kihlstrom and Laffont (1979), Kanbur (1982), Carrington et al. (1996), and Cressy (2000)), one important aspect of selfemployment is the larger variation in income compared with SW workers. On the other hand, there is a premium for self-employment as shown in the empirical study in this paper. Only the entrepreneur with high human capital can enjoy this premium for long period, though. Bates (1990) found the high human capital of entrepreneurs as a critical factor of small business longevity. In addition, Borjas and Bronars (1989) and Fairlie and Meyer (1996) report higher return to education among SE workers than SW workers using Census data. We interpret these findings as evidence of the higher return for human capital among SE workers. To summarize, we assume that higher risk and higher return for human capital characterize SE workers.

Modeling these two characteristics of the wage determination with workers' risk aversion, workers' optimal human capital investment decision produces a steeper wage profile among SW workers, as Lazear and Moore (1984) 
observed. Due to the different characteristics of SE jobs and SW jobs, SE workers are not necessarily a good 'control group' for the SW workers.

In the model, the workers choose to be SW or SE workers when they finish their schooling. Since to be SE is risky, the worker with high human capital selects SE since for these people the higher return for human capital compensates the risk. Using a standard human capital accumulation technology as in Lucas (1988), we can show that the optimal human capital investment is a function of current human capital level. Current human capital has a positive effect on human capital investment since a worker with high human capital is more efficient in additional human capital production. On the other hand, the opportunity cost of human capital investment is higher for a worker with high human capital. Under the convexity assumption of human capital production, we can show that the latter effect dominates the former effect. As a result, a worker with high human capital invests less in his human capital. Thus SE workers, who have higher human capital as a result of self-selection, tend to have a flatter wage profile compared with SW workers because of the different human capital investment behavior. We also show that the SW workers who will select SE in later periods tend to invest more in their human capital than the SW workers who plan to stay in SW jobs. In sum, SE workers invest less in their human capital on average because of two characteristics of self-employment, which are high-income risk and high return for their human capital.

The structure of the rest of this paper is as follows. Since the wage risk 
of self- employment is a crucial assumption for our main conclusion, the next section examines the wage risk for self-employed workers. The model of human capital accumulation under the income risk is introduced in the third section. The fourth section provides evidences consistent with our model. The conclusion follows.

\section{Replication of Lazear and Moore (1984)'s result and wage risk of self- employed work- ers}

\subsection{The model and estimation}

In this section, we replicate the result obtained in Lazear and Moore (1984) using a different data set; we then test to see if the wages of SE workers are more volatile than the wage of SW workers. Since we are interested in the wage variation faced by an individual, residuals from fixed-effect wage regression are used to create a measure of wage variation.

Data for the years 1985 to 1998 were taken from NLSY79. The sample is restricted to white male and is used to estimate the model:

$$
\ln w_{i t}=X_{i t} \beta_{1}+s_{i t} X_{i t} \beta_{2}+c_{i}+u_{i t}
$$

where $w_{i t}$ is hourly wage rate and $X_{i t}$ is a vector of standard control variables in Mincer type wage equation ${ }^{1}, s_{i t}$ is a dummy variable which takes one if the worker is self-employed and $c_{i}$ is individual heterogeneity. The

\footnotetext{
${ }^{1}$ The variables included in the regression appear in Table 1 . The variable names are self-explanatory.
} 
interaction with the self-employed dummy is included to replicate Lazear and Moore (1984)'s findings and to avoid systematic correlation of $u_{i t}$ with self-employment status. The model is estimated by both pooled OLS and fixed effect ${ }^{2}$. The estimation results appear in the first and second column in table 1 . The results of the fixed effect regression, which appear in the second column of table 1 , shows that SE workers earn $23.5 \%$ more ceteris paribus. The return to experience among SE workers (about $7 \%$ for the first year) is almost half of SW workers' (about 12\% for the first year). In addition, there is almost no return to tenure among SE workers while SW workers enjoy a return of $3.2 \%$ for the first year of tenure. These results almost match with the Lazear and Moore (1984)'s findings. This might be because of the Lazear contract or less on-the-job human capital investment among SE workers. In sum, SE workers earn higher wages and experience less wage growth, ceteris paribus.

Then using the residual of the previous fixed effect estimation,

$$
\hat{u_{i t}^{2}}=X_{i t} \gamma_{1}+s_{i t} X_{i t} \gamma_{2}+a_{i}+v_{i t}
$$

is estimated using both OLS and fixed effect estimation ${ }^{3}$. We are interested in the null hypothesis:

$$
H_{0}: \gamma_{2}=0
$$

The results of the multiple regression, along with the simple regression, appear in table 1. By using the results of the simple regression, we can say that

\footnotetext{
${ }^{2}$ The assumption $E\left[u_{i t} \mid X i ., s_{i,}, c_{i}\right]=0$ is posed here.

${ }^{3}$ Essentially this is Breush-Pagan's test for heteroscedasticity.
} 
the conditional wage variance among SE workers is twice or three times larger than that of the salaried workers. To avoid the possibility that the result is derived from the correlation of self-employment status with the other factors that affect wage volatility, a multiple regression is also estimated. The null hypothesis of no difference in the coefficients is rejected through F-test. Also the results are essentially the same for both OLS and fixed-effect. From these evidences, we can conclude that being self-employed is more risky than being a SW worker.

\subsection{The issues of measurement error}

There is a possible flaw with the previous analysis due to measurement error in the wage of self-employed workers. Smaller return to experience and tenure among SE workers may be due to measurement error in the wage of SE that is systematically correlated with experience or tenure. It is also likely that larger conditional variance of wage among SE workers is due to measurement error. Joulfaian and Rider (1998) report that SE workers underreport their income by $18 \%$ on average using the data from Tax Payer Compliance Measurement Program data collected by the IRS. Although respondents do not have an incentive to avoid taxation by underreporting their income in the case of NLSY, the underreporting is still possible since the respondents may refer to their 1040 form to report their income to NLSY. Thus it is worth discussing the issues of measurement error explicitly. The model with 
measurement error is assumed to be following.

$$
\begin{aligned}
& \ln w_{i t}^{*}=X_{i t} \beta_{1}+s_{i t} X_{i t} \beta_{2}+c_{i}+e_{i t}, \\
& \ln w_{i t}=\ln w_{i t}^{*}+d_{i}+b_{i} \operatorname{self}_{i t}+u_{i t},
\end{aligned}
$$

where $d_{i}$ is an individual specific tendency of misreport regardless of employment status and $b_{i}$ is an individual specific tendency of misreport of wage when the respondent is self-employed. The assumptions that these individual tendencies are time-invariant are crucial in the following discussion. These tendencies $\left(b_{i}, d_{i},\right)$ and errors in equations $\left(e_{i t}, u_{i t}\right)$ are assumed not to be correlated. The assumptions on error terms are following:

$$
\begin{aligned}
& E\left[e_{i t} \mid b_{i}, c_{i}, d_{i}, X_{i}, \text { self }_{i}\right]=0, \\
& E\left[u_{i t} \mid b_{i}, c_{i}, d_{i}, X_{i}, \operatorname{sel}_{i}\right]=0
\end{aligned}
$$

and

$$
E\left[e_{i t}^{2} \mid b_{i}, c_{i}, d_{i}, X_{i}, \text { self }_{i}\right]=\left(1+\phi \operatorname{sel}_{i t}\right) \sigma_{e}^{2}
$$

To test if self-employed worker faces the larger risk, we are interested in if $\phi=0$. The model that is actually estimated is

$$
\ln w_{i t}=X_{i t} \beta_{1}+s_{i t} X_{i t} \beta_{2}+c_{i}+e_{i t}+d_{i}+b_{i} s e l f_{i t}+u_{i t}
$$

Applying fixed effect transformation, we obtain

$$
w_{i t}-\bar{w}_{i}=\left(X_{i t}-\bar{X}_{i}\right) \beta_{1}+\left(s_{i t} X_{i t}-\overline{s_{i} X_{i}}\right) \beta_{2}+e_{i t}+u_{i t}+b_{i}\left(s e l f_{i t}-s e \bar{l} f_{i t}\right)
$$

In this situation, fixed effect estimator is not consistent estimator since $\operatorname{plim} \hat{\beta_{\text {self }}}=\beta_{\text {self }}+b$, where $b=E\left(b_{i}\right)$.Thus fixed effect estimator of $\beta_{\text {self }}$ 
estimates the lower bound of $\beta_{\text {self }}$ given $b<0$. In this case, the SE premium found in the regression should be understood as the lower bound estimate.

Another possible measurement error arises from the differential concept on the income between SW workers and SE workers. SE workers may report return for physical capital of their own business as their wage; also they may subtract the cost of physical investment in their own business from their own wage. It is likely that SE workers invest in physical capital when they start their business and collect the return later. Then the wages of short tenured SE workers are understated and the wages of long tenured SE workers are overstated. Thus the error term of the measurement error

$$
E\left(u_{i t} \mid b_{i}, c_{i}, d_{i}, X_{i .}, \text { self }_{i .}\right)=b_{i} \text { self }_{i t}+a_{i} \text { self }_{i t} \text { tenure }_{i t},
$$

where $b_{i} \leq 0, a_{i} \geq 0$, becomes a possible case. As a result the probability limit of fixed effect estimators are

$$
\operatorname{plim} \hat{\beta_{\text {self }}}=\beta_{\text {self }}+b, \quad \operatorname{plim} \beta_{\text {selftenure }}=\beta_{\text {selftenure }}+a,
$$

where $a=E a_{i}$. Therefore $\hat{\beta_{\text {self }}}$ is likely to be a lower bound estimator of $\beta_{\text {self }}$ and $\beta_{\text {selftenure }}$ is likely to be an upper bound estimator of $\beta_{\text {selftenure }}$. Therefore neither of these inconsistencies weakens our discussion. We still conclude that SE workers earn higher wage and SE workers experience less wage growth.

The conditional variance of measurement error may also depend on the self-employment status since the measurement error depends more on individuals among SE workers compared with SW workers thorough the effect 
of $b_{i}$. Define $v_{i t}=e_{i t}+u_{i t}+b_{i}\left(\operatorname{sel}_{i t}-\operatorname{sel} f_{i t}\right)$. Then

$$
E\left[v^{2} \mid X_{i t}, i\right]=\left(1+\phi \operatorname{sel} f_{i t}\right) \sigma_{e}^{2}+\sigma_{u}^{2}+E\left[b_{i}^{2}\left(\operatorname{sel} f_{i t}-s \bar{l} f_{i}\right)^{2}\right]
$$

The last term tells us that the job status changer tends to have a larger variance. However, the last term of this expression is constant for each individual, so when we regress the squared residual of fixed effect estimation of wage equation (1) on self employment status using the fixed effect, we obtain the consistent estimator of $\phi$. Thus the coefficient of self-employment status found in column 5 of table 1 (0.189 with s.e. of 0.038 ) is understood as an estimate of $\phi$. Therefore, we still conclude that the self-employment is twice as risky as being a wage-salary worker under the assumption that the tendency to misreport is constant within individual and job status.

\section{The model}

Suppose each worker lives for two periods. Each worker is endowed with one unit of time for each period. Each worker knows his ability at the first period. Each worker has the following preference with constant absolute risk aversion.

$$
\hat{U}_{i}=-\exp \left[-\gamma_{i}\left(w_{i 1}+w_{i 2}\right)\right]
$$


where $\gamma_{i}$ is the degree of absolute risk aversion of worker $i$ and $w_{i t}$ is the wage offer for worker $i$ at time $t^{4}$. The wage offer depends on job choice, whether the worker is the self-employed or salaried worker. The wage offer for each job is

$$
w_{i t S E}=b_{S E}\left(1-n_{i t}\right) h_{i t}+e_{i t S E}, e_{i t S E} \sim N\left(0, \sigma_{S E}^{2}\right)
$$

and

$$
w_{i t S W}=b_{S W}\left(1-n_{i t}\right) h_{i t}+e_{i t S W}, e_{i t S W} \sim N\left(0, \sigma_{S W}^{2}\right),
$$

where $h_{i t}$ is the human capital of worker $i$ at period $t, n_{i t} \in[0,1]$ is the portion of time devoted to the human capital accumulation by the worker $i$ at time $t$. The initial human capital $h_{i 1}$ is given as an endowment for each worker. This initial level of human capital includes human capital accumulated through education and innate ability. Although we recognize the endogeneity of the educational decision, we treat this as given since the main interest of our analysis here is on-the-job human capital accumulation. The human capital for both periods is assumed to be general across the jobs. The parameter $b_{j}$, which is exogenously given by the labor market for the workers, is the unit price of human capital in job $j$. The random variable $e_{i t j}$ is a shock to the wage. We assume $e_{i t j}$ is independently distributed across individual, time

\footnotetext{
${ }^{4}$ Although the utility function is not defined over consumption, this 'indirect' utility function is the solution of a problem such as$$
\max _{c_{1}, c_{2}}-\exp \left[-\gamma\left(\frac{\alpha}{\alpha+\beta}\right)^{-\alpha}\left(\frac{\beta}{\alpha+\beta}\right)^{-\beta} c_{1}^{\alpha} c_{2}^{\beta}\right]
$$

subject to

$$
c_{1}+c_{2}=w_{1}+w_{2} .
$$
}

The crucial assumption is that the workers do not face the liquidity constraint. 
and two jobs. By taking expectation of the life-time utility, we obtain

$$
\begin{aligned}
E \hat{U}_{i t}= & \iint-\exp \left[-\gamma_{i}\left(w_{i 1}+w_{i 2}\right)\right] d F\left(e_{i 1 j}\right) d G\left(e_{i 2 j}\right) \\
= & -\int \exp \left[\gamma_{i}\left(b_{j} h_{i 1}\left(1-n_{i 1}\right)+e_{i j 1}\right)\right] d F\left(e_{i j 1}\right) \\
& \cdot \int \exp \left[\gamma_{i}\left(b_{j} h_{i 2}\left(1-n_{i 2}\right)+e_{i j 2}\right)\right] d G\left(e_{i j 2}\right) \\
= & -\exp \left[-\gamma_{i}\left(b_{j}\left(1-n_{i 1}\right) h_{i 1}-\left(\gamma_{i} / 2\right) \sigma_{j}^{2}\right.\right. \\
& \left.\left.+b_{j} h_{i 2}-\left(\gamma_{i} / 2\right) \sigma_{j}^{2}\right)\right] .
\end{aligned}
$$

The independence of error terms across periods derives the second line and the property of log normal distribution induces the third line ${ }^{5}$. Using the ordinal property of utility function,

$$
E U=b_{j}\left(1-n_{i 1}\right) h_{i 1}-\left(\gamma_{i} / 2\right) \sigma_{j}^{2}+b_{j}\left(1-n_{i 2}\right) h_{i 2}-\left(\gamma_{i} / 2\right) \sigma_{j}^{2},
$$

is a equivalent expression of (13). Each worker has access to the following human capital accumulation technology.

$$
h_{i 2}=h_{i 1}+\delta\left(n_{i 1} h_{i 1}\right)^{\alpha}, \alpha \in(0,1),
$$

where $\delta$ is efficiency of human capital investment on human capital accumulation ${ }^{6}$. The parameter $\alpha$ represents a worker's learning ability which is assumed to be identical for all the workers. This technology shows that the worker with higher human capital is more efficient in the production of additional human capital, but the effect diminishes since $\alpha \in(0,1)$.

\footnotetext{
${ }^{5}$ When $\ln x \sim N\left(m, s^{2}\right)$, it is known that $E x=\exp \left(m+(1 / 2) s^{2}\right)$. In our case, $e=$ $\ln x \sim N\left(m, s^{2}\right)$ thus $E \exp (e)=E x=\exp \left(m+(1 / 2) s^{2}\right)$.

${ }^{6}$ This functional form of human capital accumulation is standard in the literature of macroeconomics. See Lucas (1988).
} 
Each worker maximizes his lifetime expected utility by choosing $n_{i 1}$ and a career path $\left(\{j\}_{t=1}^{2}\right)$ under constraint of human capital accumulation technology ${ }^{7}$.

Now we are going to make two assumptions that distinguish SW and SE workers.

Assumption $1 \quad \sigma_{S E}^{2}>\sigma_{S W}^{2}$.

i.e. the wages for SE workers are more volatile than those of SW workers'. The empirical evidence supports this assumption as seen in the previous section.

Assumption $2 \quad b_{S E}>b_{S W}$.

i.e. the return for human capital is higher for self-employed workers. This assumption is justified by the robust finding of the premium for the self-employment found in table 1 and this premium can be enjoyed given that the worker can remain self-employed. Whereas the failure rate of selfemployment is very high (Bates (1990), Schiller and Crewson (1997)) and Bates (1990) found high human capital of entrepreneur as a critical determinant of small business longevity. Thus the worker with high human capital exclusively enjoys the SE premium. In other word, we assume that the return for human capital is higher for SE workers. Also empirical studies which use census data report higher return to education among SE workers than SW

\footnotetext{
${ }^{7} \mathrm{As}$ a result of optimization, $n_{i 2}=0$ is trivially chosen.
} 
workers (Borjas and Bronars (1989) and Fairlie and Meyer (1996)).

Under these assumptions, we will solve the worker's maximization problem for each possible career path and calculate the corresponding indirect utility function. Each worker chooses a career path that yields the highest lifetime utility. Since we can rule out the possible career path of SE - SW ${ }^{8}$, we should consider three possible career paths of SE - SE, SW - SW, and SW - SE.

Each worker solves

$$
\max _{\left\{\left\{j_{t}\right\}_{t=1}^{2}, n_{i 1}\right\}} E U=b_{j}\left(1-n_{i 1}\right) h_{i 1}-\left(\gamma_{i} / 2\right) \sigma_{j}^{2}+b_{j} h_{i 2}-\left(\gamma_{i} / 2\right) \sigma_{j}^{2},
$$

subject to

$$
h_{i 2}=h_{i 1}+\delta\left(n_{i 1} h_{i 1}\right)^{\alpha}, \alpha \in(0,1),
$$

given $h_{i 1}$.

The optimal human capital investment time, $n_{i 1}$, is

$$
n_{i 1}= \begin{cases}(\delta \alpha)^{\frac{1}{1-\alpha}} h_{i 1}^{-1}, & \text { for job stayers. } \\ \left(\frac{b_{S E}}{b_{S W}}\right)^{\frac{1}{1-\alpha}}(\delta \alpha)^{\frac{1}{1-\alpha}} h_{i 1}^{-1}, & \text { for job changers. }\end{cases}
$$

These solutions show the human capital investment time is decreasing in the initial human capital. There are two factors that relate the initial human capital level and human capital investment. First, from (17) the worker with higher human capital is more productive in human capital accumulation. This effect is diminishing because the term $\left(n_{i 1} h_{i 1}\right)$ is exponentiated by $\alpha \in$ $(0,1)$. Second, the worker with higher human capital pays more opportunity

\footnotetext{
${ }^{8}$ This career path is always dominated by the SW - SE from the assumption 2 .
} 
cost of human capital investment, which is $b_{j} n_{i 1} h_{i 1}$. Therefore marginal benefit of investment diminishes in $h_{i 1}$ but marginal cost is constant in $h_{i 1}$, thus the worker with high $h_{i 1}$ chooses lower $n_{i 1}$. The assumption of the convexity of human capital production, $\alpha \in(0,1)$ is the crucial assumption to derive this result, after all. To summarize, under the assumption of convex human capital production technology, the worker with higher initial human capital devotes less time in his human capital investment.

By substituting the optimal $n_{i 1}$ in the objective function of each career path, we obtain the following indirect utility functions for each career path for each individual $i$.

$$
\begin{aligned}
v_{S E-S E}\left(h_{i 1}, \gamma_{i}\right)= & 2 b_{S E} h_{i 1}-\gamma_{i} \sigma_{S E}^{2}+b_{S E} \delta^{\frac{1}{1-\alpha}}\left(\alpha^{\frac{\alpha}{1-\alpha}}-\alpha^{\frac{1}{1-\alpha}}\right) \\
v_{S W-S W}\left(h_{i 1}, \gamma_{i}\right)= & 2 b_{S W} h_{i 1}-\gamma_{i} \sigma_{S W}^{2}+b_{S W} \delta^{\frac{1}{1-\alpha}}\left(\alpha^{\frac{\alpha}{1-\alpha}}-\alpha^{\frac{1}{1-\alpha}}\right) \\
v_{S W-S E}\left(h_{i 1}, \gamma_{i}\right)= & \left(b_{S W}+b_{S E}\right) h_{i 1}-\left(\gamma_{i} / 2\right)\left(\sigma_{S W}^{2}+\sigma_{S E}^{2}\right) \\
& +b_{S W}^{\frac{-\alpha}{1-\alpha}} b_{S E}^{\frac{1}{1-\alpha}} \delta^{\frac{1}{1-\alpha}}\left(\alpha^{\frac{\alpha}{1-\alpha}}-\alpha^{\frac{1}{1-\alpha}}\right)
\end{aligned}
$$

These expressions tell us that the choice of career path depends on each worker's first period human capital and the degree of risk aversion. From the first two expressions, we can clearly see that the worker with high $h_{i 1}$ is likely to be the SE worker. Those less risk adverse workers (the workers with low $\gamma_{i}$ ) are likely to choose self-employment. The relationship between lifetime utility for each career path and initial human capital is graphed in figure 1 given the degree of risk aversion. This graph shows the lifetime utility of being a SE worker is higher than being a SW worker for the high 
human capital worker. In addition, the graph shows that the worker with the 'medium' level of human capital switches the job in the middle of his career. The increasing risk aversion $(\gamma)$ increases the distance of intercepts and makes the choice of self-employment less likely.

The worker with higher initial human capital selects self-employment. How does this selection affect the wage growth of SE and SW workers? The 'average' wage growth for each career path is ${ }^{9}$,

$$
\begin{aligned}
& g_{S E-S E}=\frac{E w_{2 S E}}{E w_{1 S E}}=\frac{h_{i 1}+\delta^{1 /(1-\alpha)} \alpha^{\alpha /(1-\alpha)}}{h_{i 1}-\delta^{1 /(1-\alpha)} \alpha^{1 /(1-\alpha)}}, \\
& g_{S W-S W}=\frac{E w_{2 S W}}{E w_{1 S W}}=\frac{h_{i 1}+\delta^{1 /(1-\alpha)} \alpha^{\alpha /(1-\alpha)}}{h_{i 1}-\delta^{1 /(1-\alpha)} \alpha^{1 /(1-\alpha)}} \\
& g_{S W-S E}=\frac{E w_{2 S E}}{E w_{1 S W}}=\frac{b_{S E}}{b_{S W}} \frac{h_{i 1}+\delta^{1 /(1-\alpha)}\left(\left(b_{S E} / b_{S W}\right) \alpha\right)^{\alpha /(1-\alpha)}}{h_{i 1}-\delta^{1 /(1-\alpha)}\left(\left(b_{S E} / b_{S W}\right) \alpha\right)^{1 /(1-\alpha)}} .
\end{aligned}
$$

Interestingly, if the initial human capital is given, the wage profile of the SE and the SW workers are identical since $g_{S E-S E}=g_{S W-S W}$. This growth rate decreases and converges to one as $h_{i 1}$ increases. This is because the time devoted to human capital accumulation, $n_{i 1}$, is decreasing in initial human capital, $h_{i 1}$. However what we observe is $g_{S E-S E}<g_{S W-S W}$ because the SE worker's initial human capital, $h_{i 1}$, is higher than SW worker's. Thus the observed difference of the wage profile is the result of heterogeneity of workers in the initial human capital. The wage growth of the job changer is higher than the stayers' wage growth. The opportunity cost of human capital investment is low while being a SW worker but the return of the accumulated

\footnotetext{
${ }^{9}$ Although expected value of a ratio is not a ratio of expected values, this measure gives us a rough idea.
} 
human capital is higher since he becomes a SE worker in the second period. The low opportunity cost of the human capital investment and the high return for the accumulated human capital encourages the investment. Thus, among SW workers, prospective job changers invest more in their human capital compared with prospective job stayers.

Now, we continue our analysis using a numerical example. From the empirical findings in the previous section, we assume the variance of the wages of self-employed workers is three times as large as the salaried workers'. The return for the human capital among self-employed workers is three times larger than the salaried workers' according to assumption 2. The learning parameter is chosen such that convexity of human capital production is satisfied. Since we know little about the degree of risk aversion, the parameter of risk aversion was chosen such that a plausible result can be obtained. The parameters are assumed to be $\alpha=0.3, \gamma=15, b_{S E}=3, b_{S W}=1, \sigma_{S E}^{2}=3, \sigma_{S W}^{2}=1, \delta=0.9$. The simulation result appears in figure 2 to 4 . It is worth noting that the absolute value of the indirect utility does not mean anything. Only the order matters. From figure 2, we see that the worker with low human capital in the first period selects the career path of SW - SW. The worker with high human capital chooses the career path of SE - SE. The worker with medium level of the initial human capital chooses the career path of SW - SE.

In figure 3 the wage growth of the job stayer is drawn. As discussed before, although the wage growth of SE workers and SW workers are the same for each level of human capital, what we observe is the high wage growth for SW 
workers and the low wage growth for SE workers. However this observation is simply because of the worker's heterogeneity of the initial human capital. In figure 4 the wage growth of career changer is drawn. We can confirm the wage growth of the career changer is higher than the stayer's.

\section{Supporting evidence of the model}

\subsection{SE workers have higher human capital}

The theory discussed in the previous section predicts that the worker with higher human capital selects self-employment. With respect to the observable characteristics, several studies observe that the worker with high education is more likely to be self-employed (Borjas and Bronars (1989), Evans and Leighton (1989)). Also Bates (1990) reports that the high educational attainment of an entrepreneur is the critical determinant of small business longevity.

Borjas and Bronars (1989) observed the positive selection into SE among white males based on unobservable heterogeneity when they estimated wage equation with Heckman style selection correction assuming bivariate normal error term. The reduction of the SE premium in the fixed effect estimation relative to the SE premium in the OLS estimation in our empirical analysis also suggests positive correlation of (unobserved) individual heterogeneity and self-employment status.

It is a stylized fact that the worker who has a self-employed father is more 
likely to be a SE worker even after controlling for the inheritance ${ }^{10}$ (Lindh and Ohlsson (1996) Blanchflower and Oswald (1998), Hout and Rosen (1999) and Dunn and Holtz-Eakin (2000)).

Among the studies, Dunn and Holtz-Eakin (2000) emphasize the importance of the intergenerational transmission of human capital rather than the mitigated liquidity constraint to explain this finding, since they found very large effect of the parent's self-employment status on the son's selection into self-employment even after controlling the amount of parent's asset. They also found that the son of a successful self-employed worker is likely to be self-employed. From this finding, they conclude that the transmission of human capital is the important channel to explain intergenerational correlation of self-employment status. In addition, they did not find a stronger intergenerational correlation of occupation among self-employed workers. Thus, they speculate, the human capital that is transferred from the parents to their son is non-occupational specific human capital. Although their findings may imply the transmission of human capital that is specific to the SE, the theoretical discussion made in this paper still holds since the worker with 'any kind of' higher human capital experience lower wage growth. These results support the prediction of our model; the self-employed workers experience lower wage growth because of higher initial human capital.

The model also predicts that some of the workers plan to be self-employed

\footnotetext{
${ }^{10} \mathrm{By}$ controlling inheritance, the researchers try to partial out the effect of liquidity constraint.
} 
in the middle of their career. Several studies show that probability to be selfemployed is an increasing function of age (Borjas and Bronars (1989), Evans and Leighton (1989), and Schiller and Crewson (1997)). This finding is a very robust finding that is observed in any empirics to explain SE status. The workers who plan to be SE in the future prepares for the time by acquiring skill through OJT in the firm, thus when the worker become SE the worker is already well prepared and does not have strong incentive to acquire more skill due to high opportunity cost resulting from high human capital.

As a bottom line, several empirical studies support the prediction of the model; the worker with the higher human capital is more likely to be selfemployed.

Also the model predicts that the planned job changers accumulate more human capital while they are a salaried worker compare with the other salaried workers who plan to stay ${ }^{11}$. Lazear's model does not predict this since the wage profile of salaried worker is identical regardless of future $\operatorname{plan}^{12}$. We can test this prediction and use the result of this test as supporting evidence for the model. The prediction is tested using the following econometric model.

$$
\ln w_{i t}=X_{i t} \beta_{0}+\beta_{1} f s e l f_{i t}+\beta_{2} \exp _{i t} f \operatorname{self}_{i t}+\beta_{3} \exp _{i t}^{2} f \operatorname{self}_{i t}
$$

\footnotetext{
${ }^{11}$ Remember, (18) shows the planned job changer devotes more time in human capital accumulation relative to the stayers. Also the planned job changer has higher human capital compared with the planned job stayer.

${ }^{12}$ If the employer predicts the worker's quit in the near future, the employer may offer a steeper profile to extract the worker's effort. However this explanation is rather tricky, since the employer who notices the worker's plan to quit can fire the worker immediately to prevent him from shirking before he quits.
} 


$$
+\beta_{4} t e n_{i t} f s e l f_{i t}+\beta_{5} t e n_{i t}^{2} f \operatorname{sel} f_{i t}+c_{i}+u_{i t}
$$

where the dummy variable $f$ sel $f_{i t}$ is an indicator which takes one if the worker will be self-employed in the future at time $t^{13}$. This model is estimated by OLS and fixed effect using the sample of salaried workers under the assumption

$$
E\left[u_{i t} \mid c_{i}, X_{i .}, \exp _{i .}, f \text { self } f_{i .}, \operatorname{self}_{i .}=0\right]=0
$$

The null hypothesis that we are interested in is

$$
H_{0}: \beta_{2}=0
$$

against

$$
H_{1}: \beta_{2}>0
$$

If the null is rejected, it imply that the prospective job changer accumulate more human capital through OJT.

The regression results are in Table 2. For both OLS and fixed effect, the return to experience is $20 \%-50 \%$ higher for the prospective self-employed worker. The return to tenure is the same for the prospective self-employed workers and stayers. If we interpret the return to experience as the return for general human capital, this result is consistent with the prediction of the model. The workers who plan to be SE in the future try to accumulate general human capital before embarking upon a dangerous undertaking.

\footnotetext{
${ }^{13}$ Here we assume the perfect foresight as in the theoretical model. If we assume the rational expectation model, the estimated coefficient is subject to the attenuation bias. In this case we are estimating the lower bound of the effect.
} 


\subsection{Both winner and loser select SE?}

The model predicts a very simple selection rule; the worker with high human capital selects SE. A sensible criticism for this prediction is that there are two kinds of SE workers. The first kind is an eligible entrepreneur and the second kind is the SE worker who is not qualified to work for the firm and forced to work by himself. If this story describes the real world, it is not surprising that the latter group experience less wage growth since the less eligible worker has less learning ability and experiences less wage growth. Could we observe this kind of 'two tail selection rule' among SE workers?

To examine this possibility, we study the distribution of ability among self-employed and wage-salary workers. If there are 'two tail selection rule' among SE workers, we should find bimodal distribution of ability among SE workers that have two peaks at high and low ability. As a proxy for the ability we use AFQT89 (Armed Force Qualifying Test) score that is contained in NLSY 79. The result of kernel density estimation of the distribution of test score for the SE and SW workers appears in figure 5. Comparing two panels, we find bimodal distribution among SW workers rather than SE workers. The workers with high scores and low scores select SW. The distribution of ability among SE workers is rather unimodal. Although it is not clear why the distribution of ability among SW workers is bimodal, this evidence shows that 'two tail selection rule' among SE workers are unlikely. 


\section{Conclusion}

In this paper the human capital accumulation by self-employed (SE) and salaried and wage (SW) workers was analyzed. Under the assumptions that the wages of SE workers are more volatile than salaried workers' and the wages of SE workers more sharply reflect their human capital, SE workers invest less in their human capital because of their higher initial human capital. This difference in human capital investment behavior results in the flatter wage profile for SE than SW workers. This theory was indirectly supported by the empirical facts about self-employed workers.

The model shows that the self-employed workers are not necessarily a good 'control' group to test the Lazear contract, since not only the incentive effect of the Lazear contract produces the steeper wage profile of salaried workers, the difference of human capital investment does as well. This conclusion does not deny the existence of the Lazear contract, nor the result of Lazear and Moore (1984). However simply attributing the difference of wage profiles to the incentive effect of the Lazear contract may overestimate the importance of the Lazear contract.

A more direct test of this theory, such as the estimation of human capital investment function, is left for future research. 


\section{References}

Bates, Timothy, 1990. Entrepreneur human capital inputs and small business longevity. Review of Economics and Statistics, Vol. 72(4), pp. 551-559.

Blanchflower, David G. and Oswald, Andrew J., 1998. What makes an entrepreneur? Journal of Labor Economics, Vol. 16(1), pp. 26-60.

Borjas, George J. and Bronars, Stephen G., 1989. Consumer discrimination and self-employment. Journal of Political Economy, Vol. 97(3), pp. 581605.

Carrington, William J., McCue, Kristin, and Pierce, Brooks, 1996. The role of employer/employee interactions in labor market cycles: Evidence from the self-employed. Journal of Labor Economics, Vol. 14(4), pp. 571-602.

Cressy, Robert, 2000. Credit rationing or entrepreneurial risk aversion? an alternative explanation for the Evans and Jovanovic finding. Economics Letters, Vol. 66, pp. 235-240.

Dunn, Thamas and Holtz-Eakin, Douglas, 2000. Financial capital, human capital, and the transition to self-employment: Evidence from intergenerational links. Journal of Labor Economics, Vol. 18(2), pp. 282-305.

Evans, David S. and Leighton, Linda S., 1989. Some empirical aspects of entrepreneurship. American Economic Review, Vol. 79(3), pp. 519-535. 
Fairlie, Robert W. and Meyer, Bruce D., 1996. Ethnic and racial selfemployment differences and possible explanations. Journal of Human Resources, Vol. 31(4), pp. 757-793.

Hout, Michael and Rosen, Harvey S. Self-employment, family background, and race. Working paper 7433, NBER, 1999.

Joulfaian, David and Rider, Mark, 1998. Differential taxation and tax evasion by small business. National Tax Journal, Vol. 51(4), pp. 675-687.

Kanbur, S. M. Ravi, 1982. Entrepreneurial risk taking, inequality, and public policy: An application of inequality decomposition analysis to the general equilibrium effects of progressive taxation. Journal of Political Economy, Vol. 90(1), pp. 1-21.

Kihlstrom, Richard E. and Laffont, Jean-Jacques, 1979. A general equilibrium entrepreneurial theory of firm formation besed on risk aversion. Journal of Political Economy, Vol. 84(4), pp. 719-748.

Lazear, Edward P., 1979. Why is there mandatory retirement? Journal of Political Economy, Vol. 87(6), pp. 1261-1284.

Lazear, Edward P., 1981. Agency, earning profiles, productivity, and hour restrictions. American Economic Review, Vol. 71(4), pp. 606-620.

Lazear, Edward P. and Moore, Robert L., 1984. Incentives, productivity, and labor contracts. Quarterly Journal of Economics, Vol. 99, pp. 275-295. 
Lindh, Thomas and Ohlsson, Henry, 1996. Self-employment and windfall gains: Evidence from the swedish lottery. Economic Journal, Vol. 106, pp. $1515-1526$.

Lucas, Robert E., 1988. On the mechanics of economic development. Journal of Monetary Economics, Vol. 22(1), pp. 3-42.

Schiller, Bradley R. and Crewson, Philip E., 1997. Entrepreneurial origins: A longitudinal inquiry. Economic Inquiry, Vol. 35, pp. 523-531. 
Table 1 The replication of the Lazear and Moore (1984)'s finding and the risk of self-employed workers.

\begin{tabular}{|c|c|c|c|c|c|c|}
\hline & (1) & (2) & (3) & (4) & (5) & $(6)$ \\
\hline Method of & OLS & Fixed & OLS & OLS & Fixed & Fixed \\
\hline estimation & & Effect & & & Effect & Effect \\
\hline Dependent variable & ln wage & ln wage & $\begin{array}{c}\text { residual }^{2} \\
\text { of (2) }\end{array}$ & $\begin{array}{c}\text { residual }^{2} \\
\text { of (2) }\end{array}$ & $\begin{array}{c}\text { residual }^{2} \\
\text { of (2) }\end{array}$ & $\begin{array}{c}\text { residual }^{2} \\
\text { of (2) }\end{array}$ \\
\hline \multirow[t]{2}{*}{ education } & 0.070 & 0.092 & & 0.015 & & 0.000 \\
\hline & $(0.003)$ & $(0.007)$ & & $(0.005)$ & & $(0.018)$ \\
\hline \multirow[t]{2}{*}{ experience } & 0.063 & 0.116 & & 0.002 & & -0.023 \\
\hline & $(0.005)$ & $(0.008)$ & & $(0.008)$ & & $(0.021)$ \\
\hline \multirow[t]{2}{*}{ experience $^{2}$} & -0.001 & -0.002 & & 0.000 & & 0.000 \\
\hline & $(0.000)$ & $(0.000)$ & & $(0.000)$ & & $(0.001)$ \\
\hline \multirow{2}{*}{ tenure } & 0.052 & 0.032 & & -0.026 & & -0.010 \\
\hline & $(0.004)$ & $(0.003)$ & & $(0.006)$ & & $(0.007)$ \\
\hline \multirow[t]{2}{*}{ tenure $^{2}$} & -0.002 & -0.002 & & 0.001 & & 0.001 \\
\hline & $(0.000)$ & $(0.000)$ & & $(0.000)$ & & $(0.001)$ \\
\hline \multirow[t]{2}{*}{ self-employed } & 0.438 & 0.235 & 0.237 & 0.058 & 0.189 & -0.095 \\
\hline & $(0.173)$ & $(0.092)$ & $(0.041)$ & $(0.214)$ & $(0.038)$ & $(0.242)$ \\
\hline \multirow[t]{2}{*}{ self*educ } & -0.007 & 0.011 & & 0.004 & & 0.022 \\
\hline & $(0.011)$ & $(0.006)$ & & $(0.013)$ & & $(0.015)$ \\
\hline \multirow[t]{2}{*}{ self*exper } & -0.043 & -0.047 & & 0.018 & & 0.001 \\
\hline & $(0.020)$ & $(0.012)$ & & $(0.021)$ & & $(0.030)$ \\
\hline \multirow[t]{2}{*}{ self*$^{*} \operatorname{exper}^{2}$} & 0.002 & 0.002 & & -0.001 & & 0.000 \\
\hline & $(0.001)$ & $(0.000)$ & & $(0.001)$ & & $(0.001)$ \\
\hline \multirow[t]{2}{*}{ self*tenure } & -0.054 & -0.031 & & 0.019 & & -0.008 \\
\hline & $(0.016)$ & $(0.009)$ & & $(0.019)$ & & $(0.023)$ \\
\hline \multirow[t]{2}{*}{ self*tenure ${ }^{2}$} & 0.002 & 0.002 & & 0.000 & & 0.000 \\
\hline & $(0.001)$ & $(0.001)$ & & $(0.001)$ & & $(0.002)$ \\
\hline \multirow[t]{2}{*}{ Constant } & 5.566 & & 0.147 & 0.014 & & \\
\hline & $(0.058)$ & & $(0.009)$ & $(0.088)$ & & \\
\hline Observations & 23887 & 23887 & 23887 & 23887 & 23887 & 23887 \\
\hline Number of ID & - & 2715 & - & - & 2715 & 2715 \\
\hline $\mathrm{R}^{2}$ & 0.31 & - & - & - & - & - \\
\hline F statistics & & & & 22.35 & & 10.13 \\
\hline (p-value) & & & & $(0.000)$ & & $(0.000)$ \\
\hline
\end{tabular}

Note:

1. Standard errors are in parenthesis for coefficient estimates, the p-value is in parenthesis for the $F$ statistics. For OLS estimates, standard errors and F statistics are corrected for the panel clustering.

2. Dependent variable in the each regression (3) - (6) is the squared idiosyncratic residual of regression (2).

3. F statistics are for the null hypothesis that the idiosyncratic variance of wage of self-employed workers is same as salaried workers'.

4. Time dummies are included but coefficients not reported. 
Table 2 Wage determination of salaried worker and future self-employment.

\begin{tabular}{ccc}
\hline & $(1)$ & $(2)$ \\
\hline & ln wage & ln wage \\
education & OLS & Fixed-Effect \\
& 0.070 & 0.102 \\
experience & $(0.003)$ & $(0.007)$ \\
& 0.063 & 0.116 \\
experience & $(0.006)$ & $(0.009)$ \\
& -0.001 & -0.002 \\
tenure & $(0.000)$ & $(0.000)$ \\
& 0.054 & 0.032 \\
tenure & $(0.005)$ & $(0.003)$ \\
& -0.003 & -0.002 \\
future self & $(0.000)$ & $(0.000)$ \\
& 0.143 & 0.032 \\
fself*educ & $(0.090)$ & $(0.071)$ \\
& -0.019 & -0.008 \\
fself*exp & $(0.006)$ & $(0.005)$ \\
& 0.033 & 0.021 \\
fself*exp & $(0.013)$ & $(0.010)$ \\
& -0.002 & -0.001 \\
fself*ten & $(0.001)$ & $(0.001)$ \\
& 0.000 & 0.001 \\
fself*ten & $(0.012)$ & $(0.009)$ \\
& 0.000 & 0.000 \\
Constant & $(0.001)$ & $(0.001)$ \\
& 5.497 & \\
Observations & $(0.057)$ & 20301 \\
Number of ID & 20301 & 2648 \\
R-squared & - & - \\
\hline & 0.32 & \\
& & \\
& &
\end{tabular}

Note:

1. Standard errors are in parenthesis.

2. All the samples are salaried or wage workers.

3. future self (fself) $=1$ if the worker is self-employed in the future. Mean of this variable is 0.162 .

4. Time dummies are included but coefficients not reported. 
Figure 1

Life time utility of each career path and initial human capital

Life time utility

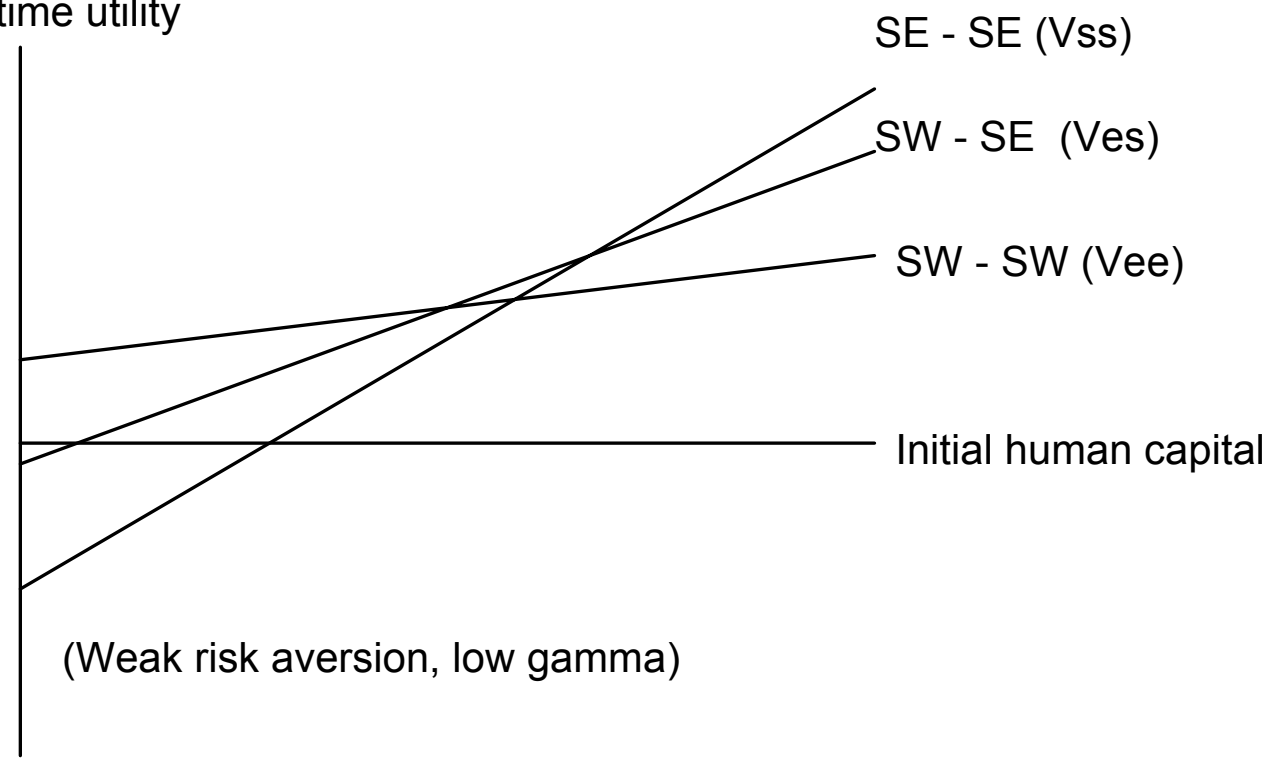

Life time utility

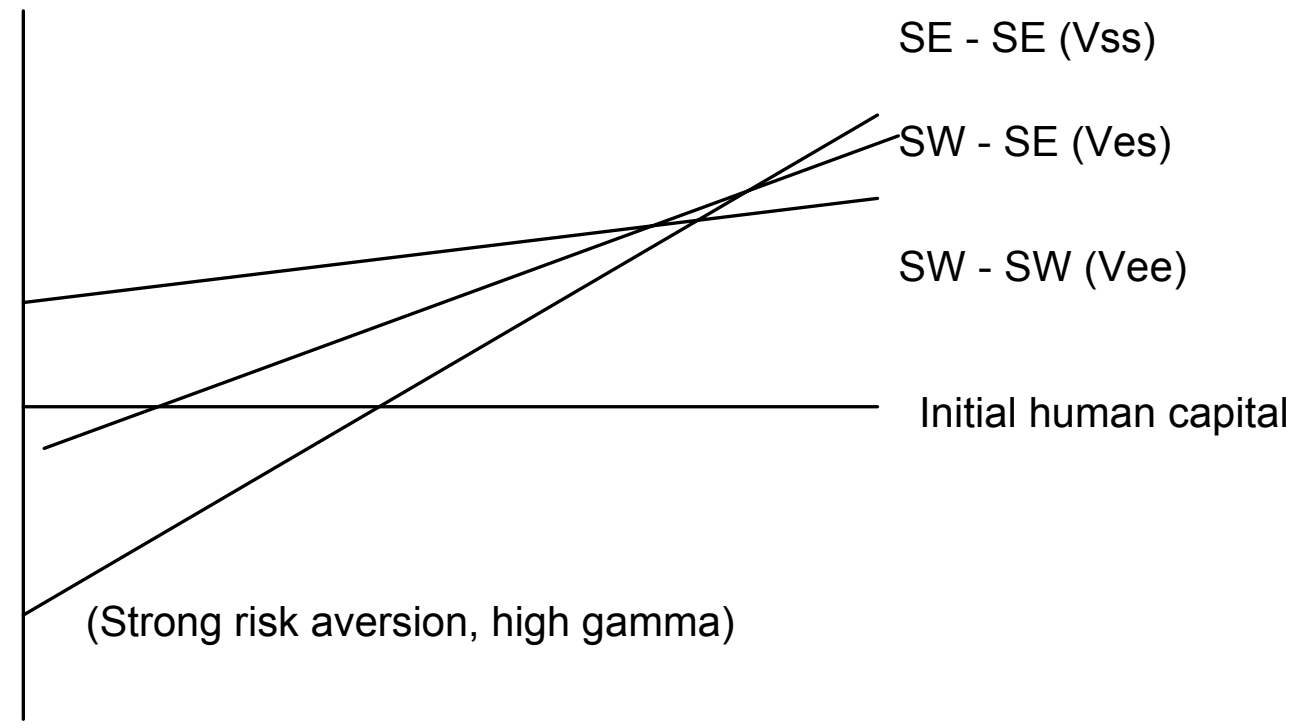

Note:

SE: Self-Employed workers.

SW: Salary and Wage workers. 
Figure 2

Life time utility of each career path and initial human capital (Numerical Example)

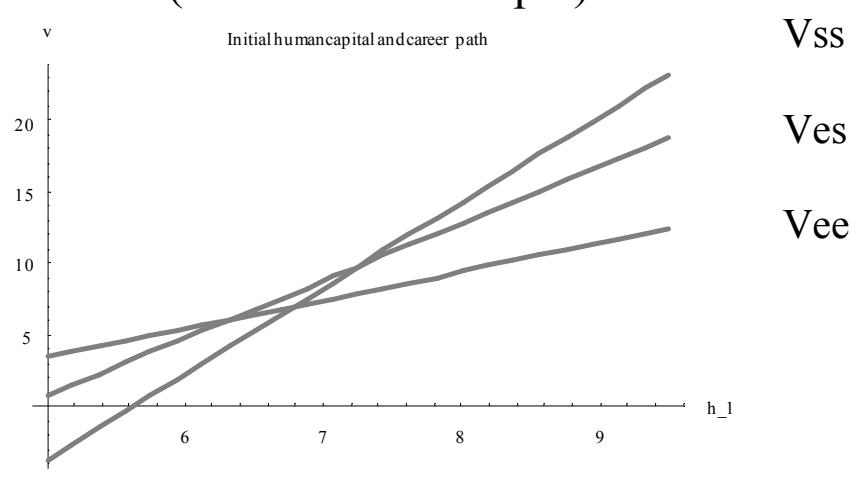

Figure 3

Wage growth of job stayers and initial human capital (Numerical example)

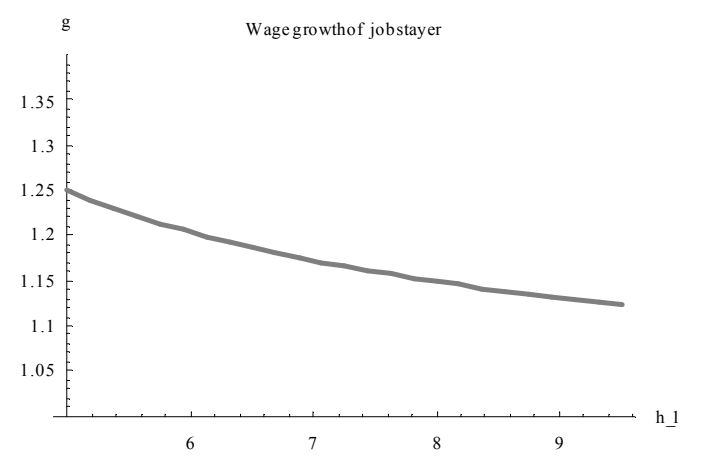

Gee $=$ Gss

Figure 4

Wage growth of job changer and initial human capital (Numerical

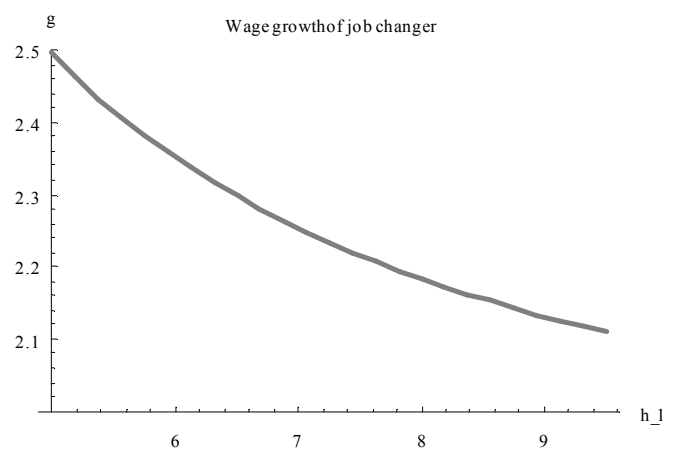

Ges 
Figure 5 Distribution of test scores among SW workers

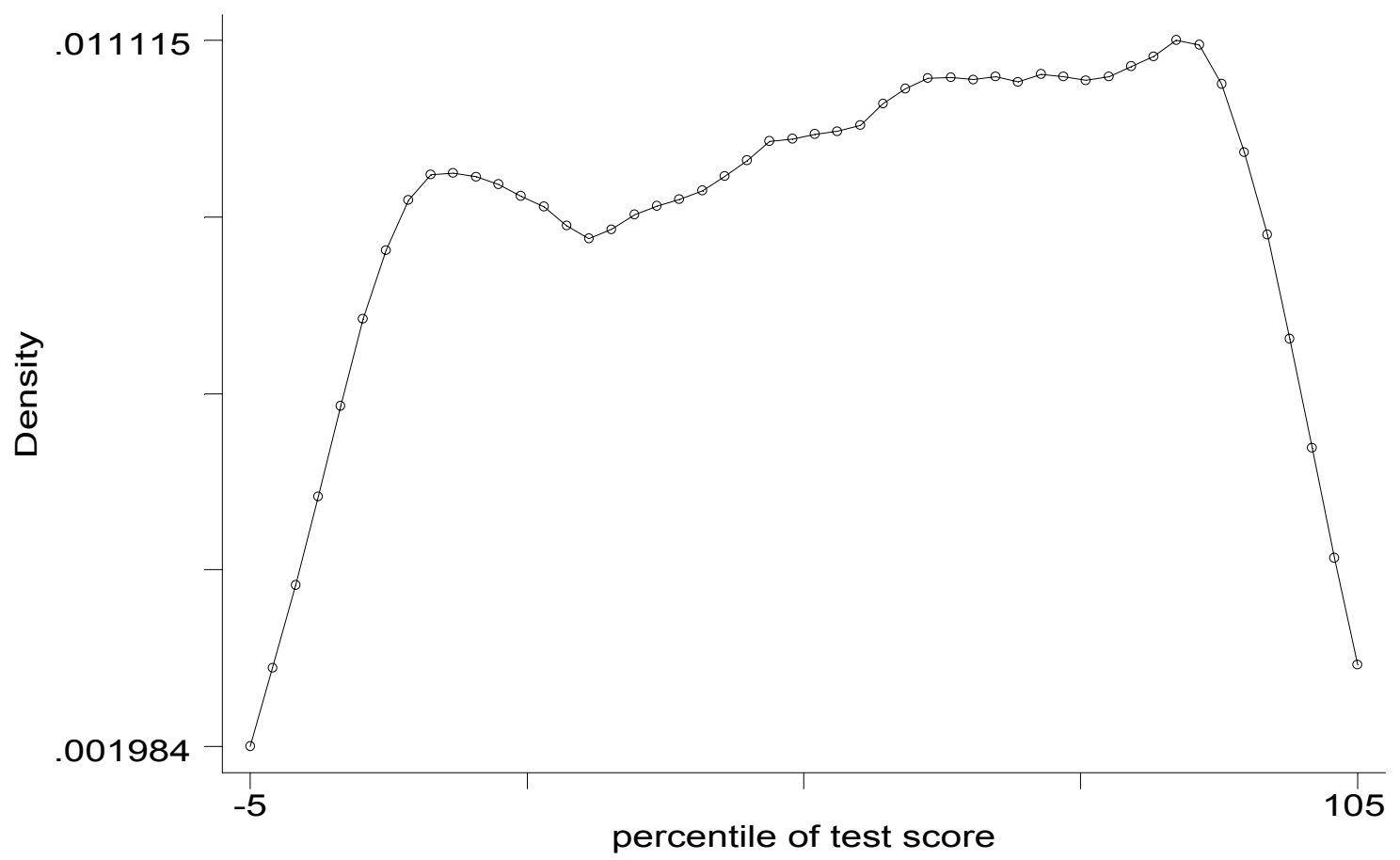

Note: AFQT89 is used as a test score. Bandwidth $=6$ and Epanechnikov kernel was used to estimate the kernel density. The distribution of percentile ranges from -5 to 105 because of the bandwidth $=6$, actual distribution of test score ranges from 1 to 99.

Figure 6 Distribution of test scores among SE workers

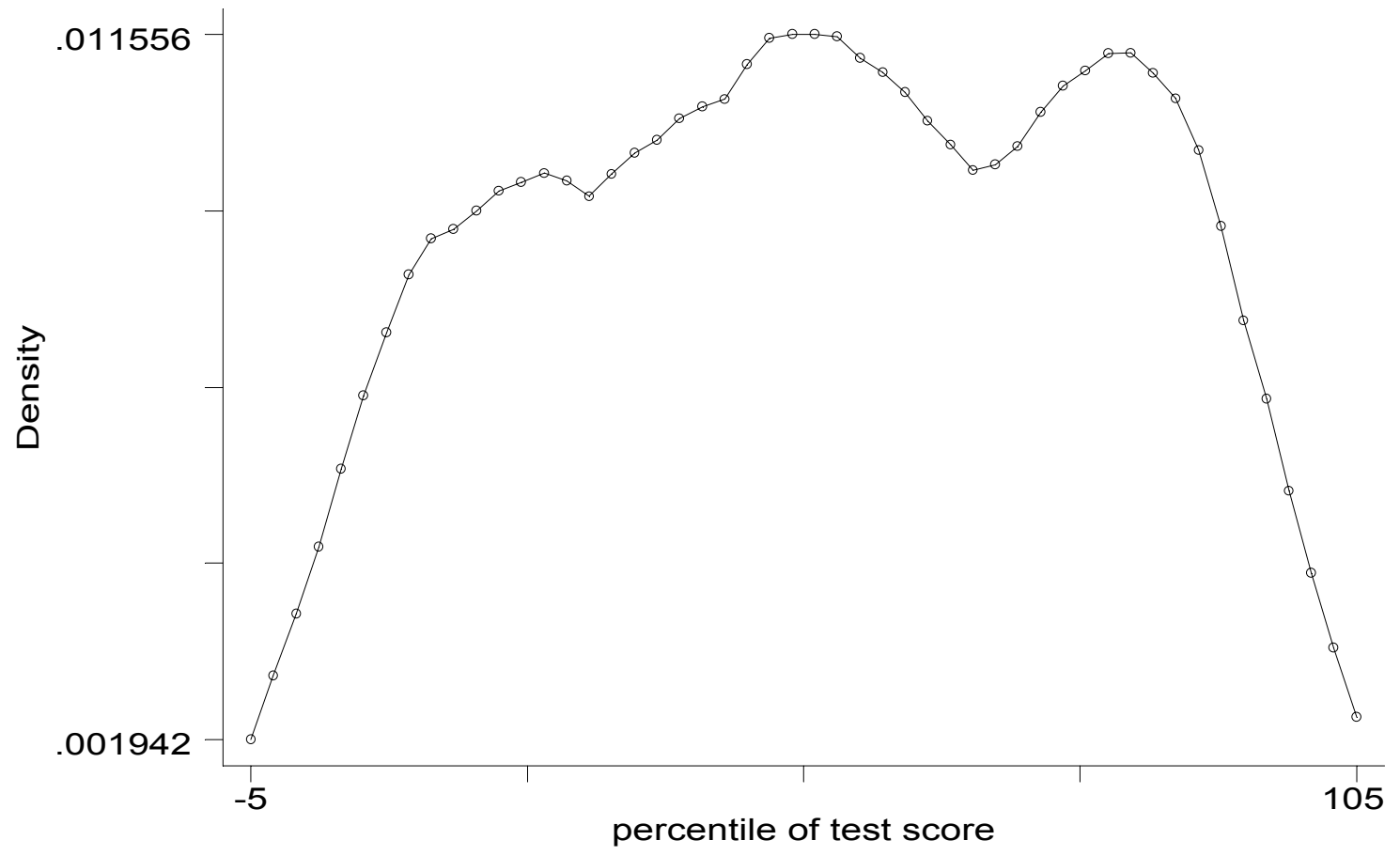

Note: Same note applies as figure 5. 